\title{
АСПЕКТЫ МЕТОДОЛОГИИ ВОСПИТАТЕЛЬНОЙ ДЕЯТЕЛЬНОСТИ В ИНЖЕНЕРНОМ ВУЗЕ В СВЯЗИ С АКТУАЛЬНЫМИ ИЗМЕНЕНИЯМИ ЗАКОНОДАТЕЛЬСТВА
}

\section{OF THE METHODOLOGY \\ OF EDUCATIONAL ACTIVITY \\ IN AN ENGINEERING HIGHER EDUCATION INSTITUTION IN CONNECTION WITH ACTUAL CHANGES TO THE LEGISLATION}

\section{S. Chizhov}

Summary: The article is devoted to the methodological aspects of improving educational work in an engineering higher educational institution in connection with current changes in the legislation on educational activities, both newly introduced by the President of the Russian Federation and already coming into force in July 2020, directly related to the formation of the specialist's personal sphere. Systemic changes, proposed as a mechanism for improving the educational component of the educational process in an engineering university, required the development of a methodological basis for the educational process in both theoretical and practical terms. The scientific article discusses a comprehensive approach, synthesizing the existing experience of educational activities with modern developments of pedagogical science aimed at the multilateral development of the personality characteristics of an engineer, in which his spiritual, moral, ethical, social spheres are targeted in an individual practical educational trajectory, allowing to realize the process of formation of professional competencies as an aspect of the formation of a sense of responsibility to society, patriotism, scientific engineering.

Keywords: education, personal sphere, competences, engineering, spirituality, morality, integrated model, pedagogical process.

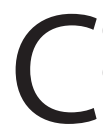
овершенствование сферы образования является осознанной необходимостью государственной политики как важный элемент обеспечения конкурентоспособности экономики страны на глобальных рынках. На протяжении последнего десятилетия в связи С принятием в 2012г. №273-Ф3 «О6 образовании в Российской Федерации» основной акцент в организации образовательной деятельности в высших учебных заведениях технического профиля был сделан на внедрение систем менеджмента качества, процессного подхода в формировании инженерных компетенций выпускника, повышение окупаемости образовательной услуги и профессиональной инженерной специализации выпускников, путём привлечения к формированию заказа на услуги профильных производственных организаций, участвующих в аттестации, практическом обучении и

\author{
чижов Сергей Владимирович \\ К.т.н., дочент, ФГБОУВО «Петербургский \\ государственный университет путей сообщения \\ Императора Александра |» \\ sergchizh@yandex.ru
}

Аннотация: Статья посвящается методологическим аспектам совершенствования воспитательной работы в инженерном высшем учебном заведении в связи с актуальными изменениями законодательства 06 образовательной деятельности, как вновь внесёнными Президентом РФ, так и уже вступающими в силу в июле 2020г., непосредственно связанным с формированием личностной сферы специалиста. Системные изменения, предлагаемые в качестве механизма совершенствования воспитательной составляющей образовательного процесса в инженерном ВУЗе потребовали разработки методологической основы образовательного процесса как в теоретическом, так и В практическом отношении. В научной статье рассматривается комплексный подход, синтезирующий имеющийся опыт воспитательной деятельности с современными разработками педагогической науки, нацеленными на многостороннее развитие свойств личности инженера, в котором его духовная, нравственная, этическая, социальная сферы являются целевыми в индивидуальной практической образовательной траектории, позволяющими реализовать процесс формирования профессиональных компетенций как аспект формирования чувства ответственности перед обществом, патриотизма, научного инженерного творчества.

Ключевые слова: воспитание, личностная сфера, компетенции, инженерное творчество, духовность, нравственность, интегрированная модель, педагогический процесс.

трудоустройстве студентов. Это в определённой степени способствовало адаптации учебного процесса к современном потребностям производства, вместе с тем обнаружив острую необходимость развития личностных свойств специалиста, характерных для отечественной инженерной школы, таких как ответственность, нравственность, патриотизм, творческое отношение к профессии, что достигалось в отечественном образовании различными методами воспитания, важность которого в полной мере не была осознана в современном образовательном процессе до настоящего времени и не подвергалась изменениям в методическом и организационном аспекте.

Внесение Президентом РФ В.В. Путиным в мае 2020г. поправок к закону, касающихся сферы воспитания, как 
осознанной деятельности по развитию личности, её социализации и самоопределения, в основу которых должны быть положены социо-культурные, духовные, нравственные ценности, определяющие мотивы поведения в пользу человека, семьи, государства, общества и направленные на развитие гражданственности и патриотизма, уважение памяти защитников Отечества, подвига Героев, человека труда, закона, правопорядка, старшего поколения, взаимоуважения, сохранения наследия культуры, многонациональных народных традиций РФ, а также природы и окружающей среды делает актуальным и является основой для совершенствования сферы воспитания как части образовательного процесса как в инженерном ВУЗе, так и во всей системе образования РФ.

Указанные обстоятельства определили цель исследования, заключающуюся в формировании эффективной педагогической модели, сочетающую современные технологии специального образования и деятельность по воспитанию обучающегося, направленную на формирование личностных качеств и процесс формирования профессиональных инженерных компетенций. Для достижения цели в исследовании решается две задачи.

Первая задача состоит в анализе возможных подходов к трансформации и повышению эффективности воспитательной деятельности для достижения целей в области подготовки специалистов, регламентируемых ОПОП в инженерном ВУЗе на базе уже выстроенных процессов менеджмента.

Вторая задача заключается в определении педагогических механизмов интеграции изменений в сфере воспитания с практическим и практико-ориентированным формами обучения, вступающими в законную силу с 1 июля 2020г.

Анализ и оценка эффективности организации современного образовательного процесса по инженерным направлениям при учёте результатов, полученных другими авторами [3] и реализуемый в рамках решения первой задачи, в соответствии со стандартами системы менеджмента качества проводилась на базе методического совета по специализации «мостостроение», являющуюся одной из старейших инженерных специальностей в России, сформированной на основе школы прикладной механики в Институте корпуса путей сообщения в СанктПетербурге, основанного в 1809г., ныне ФГБОУ ВО Петербургский государственный университет путей сообщения Императора Александра I, в 2019г. - 2020г.

Результаты оценки свидетельствуют о том, что изменения в образовательной деятельности по инженерным специальностям, проводимым в последнее десятилетие, был сделан на реализацию процессного подхода, на- правленного на формирование определённых технических и гуманитарных компетенций, без достаточного учёта потенциала воспитания как нравственной, этической категории, направленной на профессиональную инженерную социализацию будущего специалиста.

Современное содержание педагогического процесса, подготовки, образования, воспитания российских инженеров, невозможно представить без понимания эволюции ключевых её элементов. Во время становления российской инженерной школы воспитание стало фундаментом образовательной деятельности. Являвшиеся по своей сути воспитанниками инженерных учебных заведений, курируемых первыми лицами государства, в своём образовании российские инженеры основывались на духовно-нравственных, светских этических традициях, представлениях о личности инженера и своём месте в окружающем мире, в которые инкорпорировались передовые научные достижения в области механики, математики, геометрии. При этом традиции отечественного светского воспитания, ставшие основой воспитания инженеров к концу IXX века и во-многом заложенные в Петербургском воспитательном доме в 1797г., ныне ФГБОУ ВО «Российский государственный педагогический университет имени А.И. Герцена» были после 1917 г. развиты в интересах человека в виде стройной методологии [4] отечественными педагогическими, инженерными школами ВУЗов Москвы, Новосибирска, других научных центров в XX веке.

Стройная система образования советского периода, развивавшаяся с учётом идеологических принципов, но при этом имевшая научный, объективистский, системный характер сделала доступными методы образования и воспитания широкому кругу обучающихся и впитав классические традиции инженерной школы в части методологии обучения закрепила образовательный потенциал в системе получения специальных знаний. Вместе с тем, идеологические целевые установки воспитания инженеров при формировании личностных качеств специалиста в полной мере не позволяли развить сферу инженерного мышления в ключе здорового индивидуализма, хоть и основанного на коллективном взаимодействии в достижении целей, но догматически ограничивавшего её в индивидуальном конкурентном характере принятия, реализации и воплощения инженерных решений широким кругом субъектами экономической деятельности.

В годы смены политического и экономического уклада страны система подготовки технических специалистов в полной мере не использовала в педагогическом процессе имеющийся потенциал воспитательной деятельности, развития личностных свойств специалиста, оказывающих влияние на инженерное мышление, заложенные в предшествующие периоды. При этом струк- 
тура педагогического процесса в переходный период, содержащая в принципиальном классическом понимании его функциональные элементы образования, воспитания и развития личности обучающегося носила во многом дезинтегрированный характер, не учитывая в полном объёме целеполагание и взаимодействие этих элементов друг с другом для достижения общей цели.

Таким образом, трансформация и повышение эффективности подходов воспитательной деятельности в инженерном ВУЗе может основываться на модели, сочетающей в себе классические, методологически развитые в XX веке принципы и современные процессные образовательные технологии, рисунок 1.

Так, в ФГБОУ ВО «Петербургский государственный университет путей сообщения Императора Александра |» в образовательный процесс уже интегрированы методы воспитания, направленные на профессиональную инженерную социализацию обучающихся при освоении рабочих программ специалитета.

Например, в курсе «История мостостроения» специализации «Мостостроение», реализуемой на кафедре «Мосты», факультета «Транспортного строительства» используются формы, предполагающие возможность освоения программы, включая выполнение контрольных заданий путём изучения деятельности, научного вклада и имплементации решаемых инженерных задач к современным практическим, производственным задачам на основе работ основоположников школы прикладной механики, заложивших основы инженерной деятельности в России в начале XIX века, работавших в университете Габриэля Ламе, М.В. Остроградского, Д.И. Журавского, Н.А. Белелюбского, С.В. Кербедза и целой плеяды выдающихся инженеров этого времени, работавших в Университете.

Образовательная программа реализуется при методической помощи и поддержке старейшего техническо-

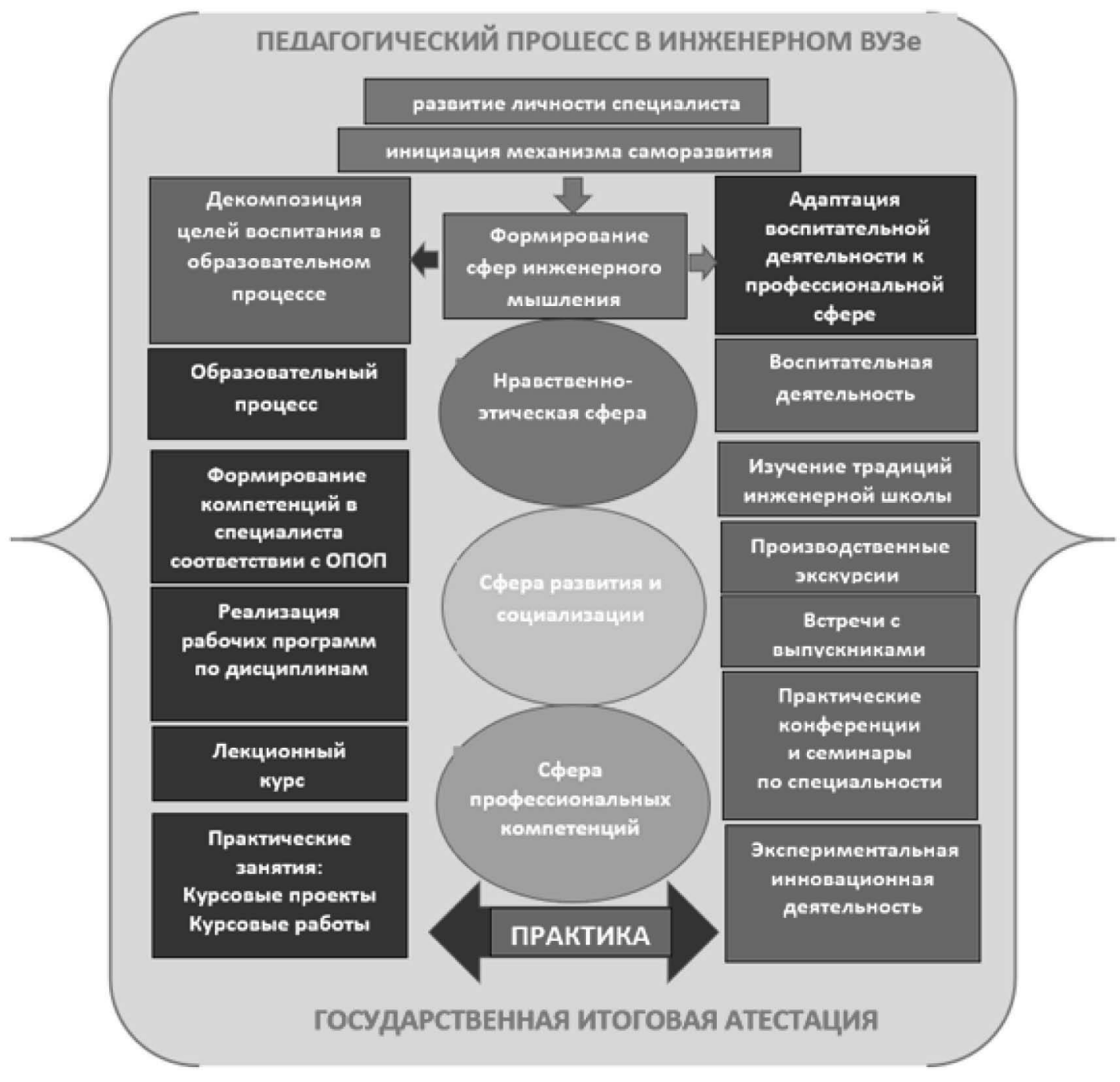

Рис 1. Интегрированная модель педагогического процесса в инженерном ВУЗе. 
го музея России - Центрального Музея Железнодорожного Транспорта России (ЦМЖТ России), основанного практически одновременно с Университетом в 1813г. и сохранившего уникальную научную коллекцию моделей мостов, построенных великими инженерами в России и за её пределами. На специальной выставочной площадке, где располагается экспозиция проводятся демонстрация и технические экскурсии, а также проходят открытые лекции и обсуждения при использовании обоснованных с научных педагогических позиций [6] по изучаемому предмету научных инженерных достижений этапа становления отечественной инженерной школы.

Анализ методов реализации интегрированной модели свидетельствует, что аспект социализации в воспитании специалиста может быть эффективным при системном подходе в педагогическом процессе, в котором развитие личности специалиста рассматривается в тесной взаимосвязи с деятельностью по достижению образовательных и воспитательных целей, основанных на инициации механизмов саморазвития личности инженера. Базовым принципом такой модели педагогического процесса является формирование личностных сфер инженерного мышления, интегрирующих нравственно-этический, социализирующий и профессиональный компетентностный элементы [7]. Реализация такой модели требует качественного совершенствования системы преподавательской деятельности в инженерном образовании, предполагающего обеспеченность педагогического процесса подготовки инженеров профессорско-преподавательским составом, обладающим не только профессиональными инженерными компетенциями, но и осознающим особенности формирования механизмов развития личности специалиста [5]. Примером такой инновационной педагогической практики является магистерская программа по направлению: «Инженерная аксиология», утверждённая к разработке и реализации на базе Института Педагогики» ФГБОУ ВО «Российский государственный педагогический университет имени А.И. Герцена» в которой кафедра «Мосты», вышеназванного Университета выступает партнёром.

В контексте совершенствования законодательства в сфере образования, направленных на совершенствование практико-ориентированных механизмов инженерного образования, как второй задачи настоящего исследования в части интеграции педагогических подходов, является реализация комплекса системных изменений. Апробация модели была проведена в образовательном процессе кафедры «Мосты» ПГУПС Императора Александра в течение 2018-19; 2019-20 учебного года. Установлено, что заинтересованность и результативность освоения программ специалитета обучающимися по специализации существенно возрастает при реализации модели в условиях самомотивации [1].
Во-первых, это достигается планированием и декомпозицией целей воспитательной деятельности в образовательном процессе. Как показала практика, образовательные программы, реализуемые на принципах актуальности, практической значимости и новизны инициируют механизмы саморазвития и способствуют стремлению к освоению обучающимися профессиональных компетенций, связанных с разработкой, созданием и реализацией нового успешного инженерного продукта.

Во-вторых, основания воспитания специалистов, интегрированные с механизмами саморазвития, В котором нравственные, этические принципы рассматриваются в качестве базовых, дают основания для самоидентификации специалиста и его развития в культурно-историческом профессиональном контексте и определяют направления для поиска инновационных профессиональных решений, учитывающих достижения инженерной школы и мирового опыта.

В-третьих, практико-ориентированные предметы, основанные на реальных производственных процессах ведущих компаний позволяют приблизить образовательный процесс к производственному, что не только повышает востребованность специалистов у работодателя в профессиональной сфере, но и создаёт возможности для инкорпорирования компетенций специалиста в развитие малого и среднего бизнеса, основанного на интеллектуальном потенциале выпускников, разрабатывающих узкопрофильные инженерные задачи. Этот подход в принципе является унифицированным в части инженерной деятельности, вместе с тем примером такого практико-ориентированного, более узкого специализированного взаимодействия Санкт-Петербургской инженерной школы мостостроения с ведущими проектными организациями является реализация интегрированной модели при поддержки ведущих проектных институтов АО «Институт Гипростроймост Санкт-Петербург»; АО «Институт «Стройпроект»; АО «ТРАНСМОСТ»; ООО ПИИ «Севзапмостпроект» и др. [2].

В качестве вывода о готовности к реализации изменений в законодательстве в сфере профессионального инженерного образовании следует отметить, что они своевременны и дают основания для повышения эффективности подготовки специалистов. Её показатели будут связаны с готовностью системы высшего профессионального образования к реализации неформального подхода в воспитательной деятельности, интегрированной с образовательным процессом, основанном на развитии личности специалиста, возможный подход к которому в виде интегрированного педагогического процесса предложен в настоящей статье. 


\section{ЛИТЕРАТУРА}

1. Ахметгареева Р.К. Педагогические проблемы подготовки линейных инженеров с творческим стилем мышления // Казань: Вестник НЦБЖД. 2020. №1(43). C. 5-8.

2. Белый А.А. Корпоративный метод производственного обучения на кафедре «Мосты» ФГБОУ Во ПГУПС Белый А.А. Чижов С.В. // Санкт-Петербург: В сборнике: Профессиональное образование, наука и инновации в XXI веке сборник трудов ХІІ Санкт-Петербургского конгресса. 2018. С. 24-25.

3. Годлевская Е.В., Лихолетов В.В. Концептуальная модель формирования системной инженерной компетентности: сущность и дидактический инструментарий // Челябинск.: Инженерное образование. 2018. №24. С.85-93.

4. Глубокова Е.Н., Писарева С.А. Воспитательный потенциал университетского образования педагога// Санкт-Петербург: В сборнике Воспитание и социализация в современной социокультурной среде. Санкт-Петербург, РГПУ им. А.И. Герцена. Сборник научных статей Международной научно-практической конференции.2019. С.14-19.

5. Козлова А.Г. Инженерная аксиология, как составляющая образовательного процесса// Среднее профессиональное образование. 2016. М: №9. С.12-14.

6. Писарева С.А., Тряпицына А.П., Введение в проблематику дискуссионной площадки// Санкт-Петербург: В книге: Современная школа научно-методические материалы. Российский государственный университет им. А. И. Герцена, 2019. С.5-8.

7. Фаритов А.Т. К вопросу понятия «инженерная компетенция» в педагогической теории// М: Научное обозрение. Педагогические науки. 2019. №6. С.53-59.

(с Чижов Сергей Владимирович (sergchizh@yandex.ru).

Журнал «Современная наука: актуальные проблемы теории и практики»

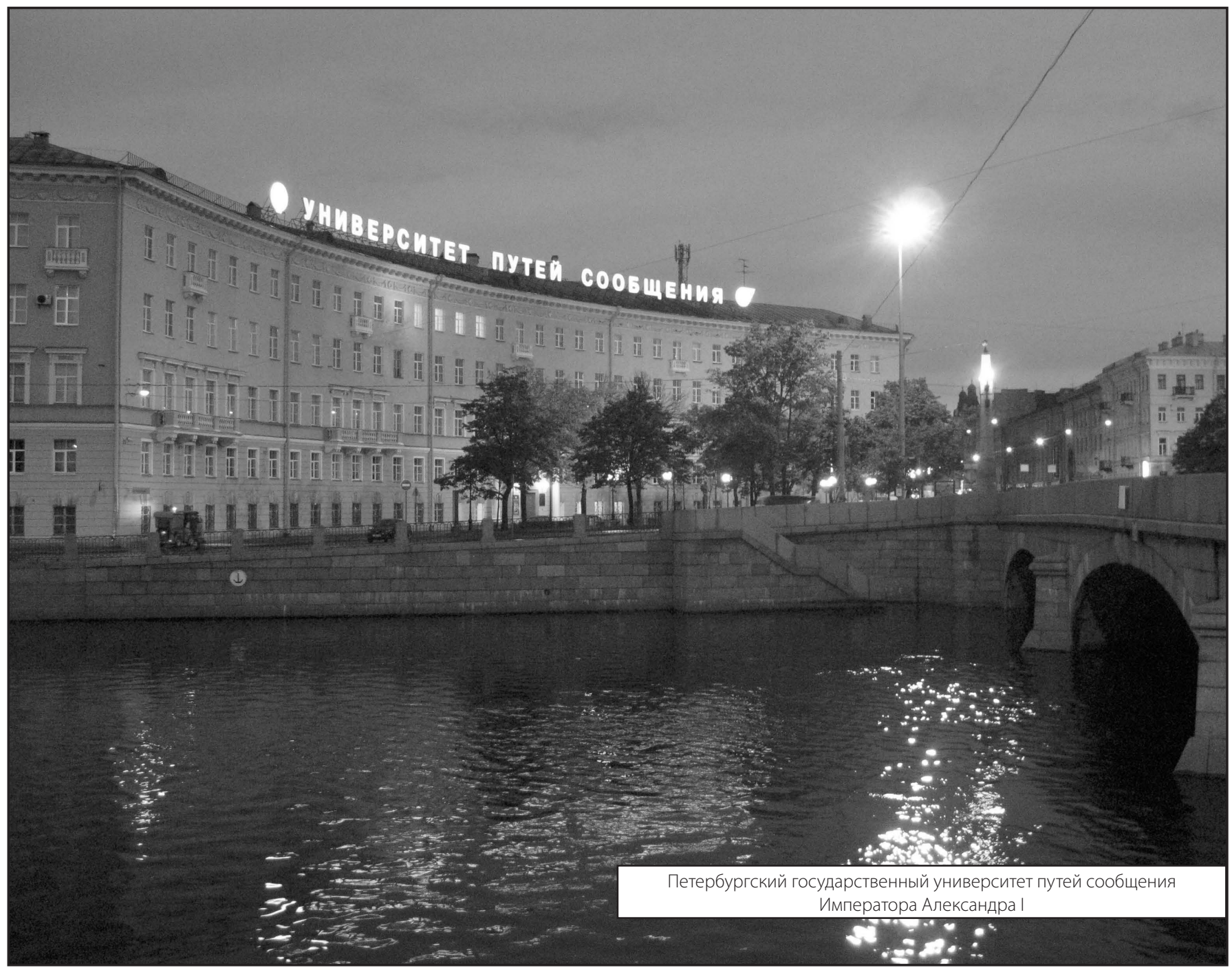

